\title{
ANGIOGRAPHIC STUDY OF ANATOMICAL VARIATIONS OF CORONARY ARTERIES BY USING DIAGNOSTIC CATHETER
}

\author{
Marwa Tharwat*,Mamdouh A.El Ashtokhy*, Ragab Abdelsalam Mahfouz**, Amal Alshahat Ibrahim*, \\ *Department of anatomy \& embryology, ** Department of Cardiology, Faculty of Medicine, Zagazig University.
}

\begin{abstract}
Introduction:The coronary arteries may present several anomalies, in terms of both number and position. New image-based diagnostic techniques have led to greater reliability in the identification of these anomalies.Aim of the work:this work is done to study the angiographic pattern of normal coronary arteries variations by using the diagnostic catheter.Material and Methods: Any patient enlisted for angiography in catheterization lab in Zagazig University Hospital was enrolled in this study.Results: Data of 4246 patients who underwent coronary angiography were analysed. 115 patients who had anomalous of coronary arteries were entered into final data analysis. The following data could be concluded: The overall incidence of primary congenital coronary anomalies was $2.7 \%$ (115 out of 4,246 patients) in our angiographic population, of whom 86 were males $(74.7 \%)$ and 29 were females $(25.3 \%)$. The mean age was $(45.95 \pm 11.65)$ years. Anomalous LCX was the most common coronary anomaly being present in 35 patients $(0.82 \%)$. The second most common anomaly was myocardial bridge and it was present in 31 patients $(0.73 \%)$. Anomalous RCA was present in eighteen patients (15.65\%). Left main coronary artery was absent in two cases (1.7\%) and it has anomalous origin from right coronary sinus (RCS) in another two cases $(1.7 \%)$. On the other hand, anomalous LAD was present in 8 patients $(6.95 \%)$. Coronary aneurysms were observed in 10 cases $(7.82 \%)$. On the other hand, coronary fistulas were diagnosed in nine cases $(8.7 \%)$. The incidence of coronary anomalies among cases with coronary artery detected disease was $72.2 \%$ (83 cases) while this incidence among those without angiographically detected coronary artery disease was $27.8 \%$ (32 cases). Hence, the frequency of coronary artery anomaly was significantly higher among patients with CAD than those without CAD ( $\mathrm{P}<0.0001)$. Conclusion:Coronary artery anomaly is a common anomaly between the populations. It could be the only cause of chest pain without significant coronary lesion.
\end{abstract}

\section{INTRODUCTION}

$V$ ariations in coronary anatomy are often recognized in association with structural forms of congenital heart disease. Understanding the pathophysiology is important in guiding management because variations in coronary are common, and the prognosis depending on anatomical features. Because of considerable heterogeneity of coronary vasculature, what is considered atypical, abnormal, aberrant, anomalies of, accessory, ectopic, incidental, variant, or significant is often unclear. The terms Anomalies of or abnormal are used to define any variant form observed in less than $1 \%$ of the general population

\section{AIM OF THE WORK}

The aim of this work is to study the angiographic pattern of normal coronary arteries variations by using the diagnostic catheter.

\section{SUBJECTS \& METHODS}

This is a descriptive study which was carried out in catheterization unit in Zagazig university hospital .The subjects were recruited from all lists of patients suffering from chest pain and were indicated for coronary angiography in the period from 1/2012 till 1/2014.

Inclusion criteria: Any patient enlisted for coronary angiography in catheterization lab unit in Zagazig
University Hospital will be enrolled in this study. We included all patients of all age and sex groups.

Exclusion criteria :Patients with coronary anomalies occurring as a result of congenital heart disease, Patients with previous history of coronary artery intervention (balloon or stenting),Patients with previous history of coronary artery bypass graft surgery.

Methodology:I-All patients had signed an informed consent stating that their imaging results may be used anonymously for research purposes. Local ethics in research committee of our center had approved this study.

II-The coronary angiograms of 4226 patients with symptomatic heart disease were analyzed and those with anomalous coronary arteries were selected for further assessment.

III-Data collected about each patient includes: Coronary artery anatomy.,Variations in coronary arterial circulation.,Abnormalities in coronary arteries which include abnormal site, size, origin, course, number, termination or structure., The dominance of the heart. ,

IV-Coronary angiography: was performed via Judkins femoral technique using a 6-inch image intensifier,we tried to investigate the presence of a variety of coronary anomalies, particularly focusing on major anomalies, in the angiographic study of 
patients to determine the prevalence of various types of anomalies and their anatomic variation in a selected adult population in Sharkia, at least two independent investigators reviewed the films, most of the selective coronary angiographies were performed by the Judkins (femoral) method, although some were done according to the method of Sones (brachial).

V- Statistical analysis:The data were collected by a check list and were underwent statistical analysis.

The prevelance of coronary artery anomaly was calculated. The data of the present study were checked and entered to Statistical Package of Social Science (SPSS) version 10. The data were presented by using the following tests ${ }^{(2)}$ :

\section{Level of Significance:}

, P- values were considered as follow

- $\mathrm{P}$ value $>0.05=$ Non Significant $(\mathrm{NS}) . \quad \mathrm{P}$ value $\leq 0.05=$ Significant $(*)$.
- $\mathrm{P}$ value $<0.01=$ Highly Significant $(* *) \quad . P$ value $<0.001=$ Very Highly Significant $(* * *)$

\section{RESULTS}

Data of 4246 patients who underwent coronary angiography were analysed. One hundred and fifteen patients who had anomalous of coronary arteries were entered into final data analysis. Angiography was indicated to evaluate the coronary artery disease in these patients.

The overall incidence of primary congenital coronary anomalies was $2.7 \%$ (115 out of 4246 patients) in our angiographic population, of whom 86 were males $(74.7 \%)$ and 29 were females $(25.3 \%)$. The mean age was $(45.95 \pm 11.65)$ years, with a range between 28 and 75 years.

The coronary dominance pattern was $63.02 \%$ as RCA dominant,(posterior interventricular artery arise from RCA) $25.57 \%$ as LCA dominant ,(as posterior interventricular artery arise from LCX artery) and $11.39 \%$ as co-dominant , ( as posterior interventricular artery arise from both RCA\&LCX).

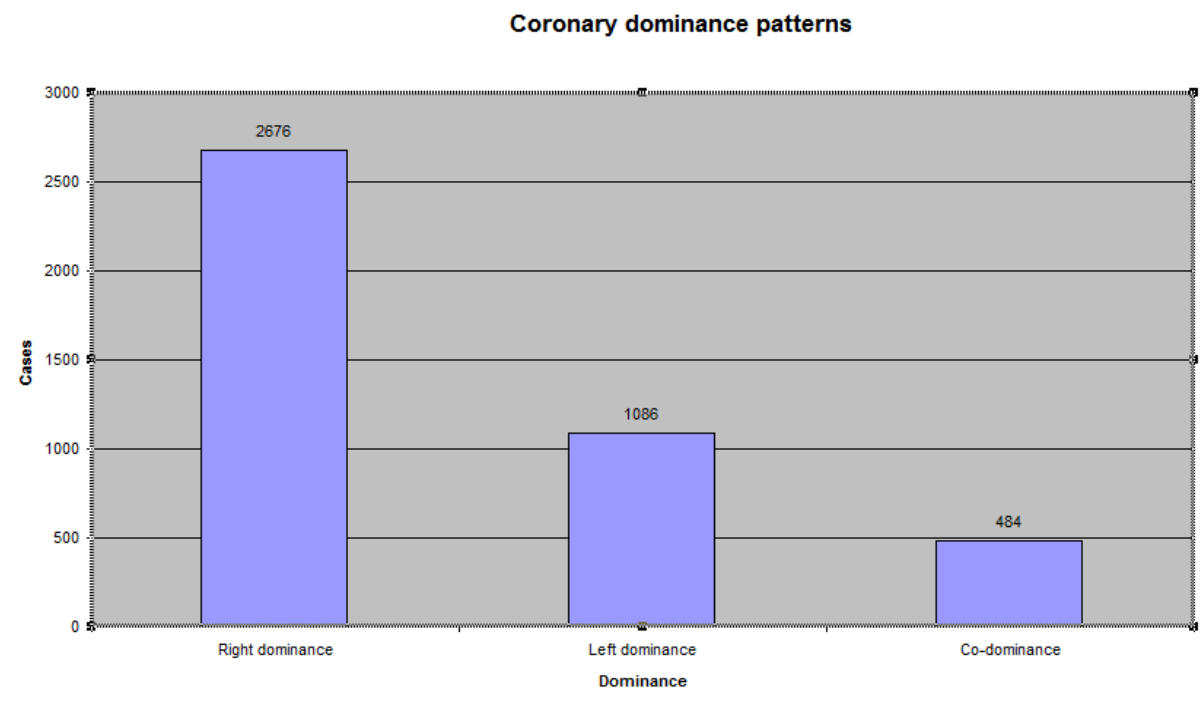

Figure1: coronary artery dominance pattern. 
Table (1): Incidence of different congenital coronary artery anomalies in population doing coronary angiography (number $=4246$ )

\section{Coronary anomaly}

\section{Number of patients}

Angiographic incidence (\%)of anomalous

\begin{tabular}{lccc}
\hline $\begin{array}{l}\text { Anomalous origin of LCX } \\
\text { from RCS/RCA }\end{array}$ & $\mathbf{3 5}$ & $30.34 \%$ & $0.82 \%$ \\
\hline Anomalous origin of RCA & $\mathbf{1 0}$ & $8.7 \%$ & $0.235 \%$
\end{tabular}

from LCS/LAD

\begin{tabular}{llll}
\hline RCA arising from PSV & $\mathbf{8}$ & $6.95 \%$ & $0.188 \%$ \\
\hline Absent LMC & $\mathbf{2}$ & $1.73 \%$ & $0.047 \%$ \\
\hline $\begin{array}{l}\text { Anomalous origin of } \\
\text { LMCA }\end{array}$ & $\mathbf{2}$ & $1.73 \%$ & $0.047 \%$ \\
\hline Anomalous LAD from RCS & $\mathbf{8}$ & $6.95 \%$ & $0.188 \%$ \\
\hline Coronary fistulas & $\mathbf{9}$ & $7.82 \%$ & $0.212 \%$ \\
\hline Aneurysm & $\mathbf{1 0}$ & $8.7 \%$ & $0.235 \%$ \\
\hline Myocardial bridge & $\mathbf{3 1}$ & $26.95 \%$ & $0.73 \%$ \\
\hline $\begin{array}{l}\text { Prevalence of all } \\
\text { Anomalous coronary artery }\end{array}$ & $\mathbf{1 1 5}$ & $100 \%$ & $2.7 \%$ \\
\hline
\end{tabular}

LCX:left circumflex $\quad$ RCS:right coronary sinus $\quad$ LCS:left coronary sinus artery

PSV: posterior sinus of valsalva

LMCA: lrft main coronary artery

RCA:right coronary descending

LAD: left anterior

From table(1) it was found that anomalous LCX was the most common coronary anomaly being present in 35 patients ( $\mathbf{0 . 8 2} \%$ ) with angiographic incidence of $30.34 \%$. It originated from the right sinus in 15 patients as shown in fig.(2) and from the RCA in 20 patients. Its proximal course was retroaortic in all cases. Peripheral distribution of the LCX artery was normal in all of them. The left anterior descending coronary artery in all of them originated from a separate ostium in the left sinus and had a normal distribution.

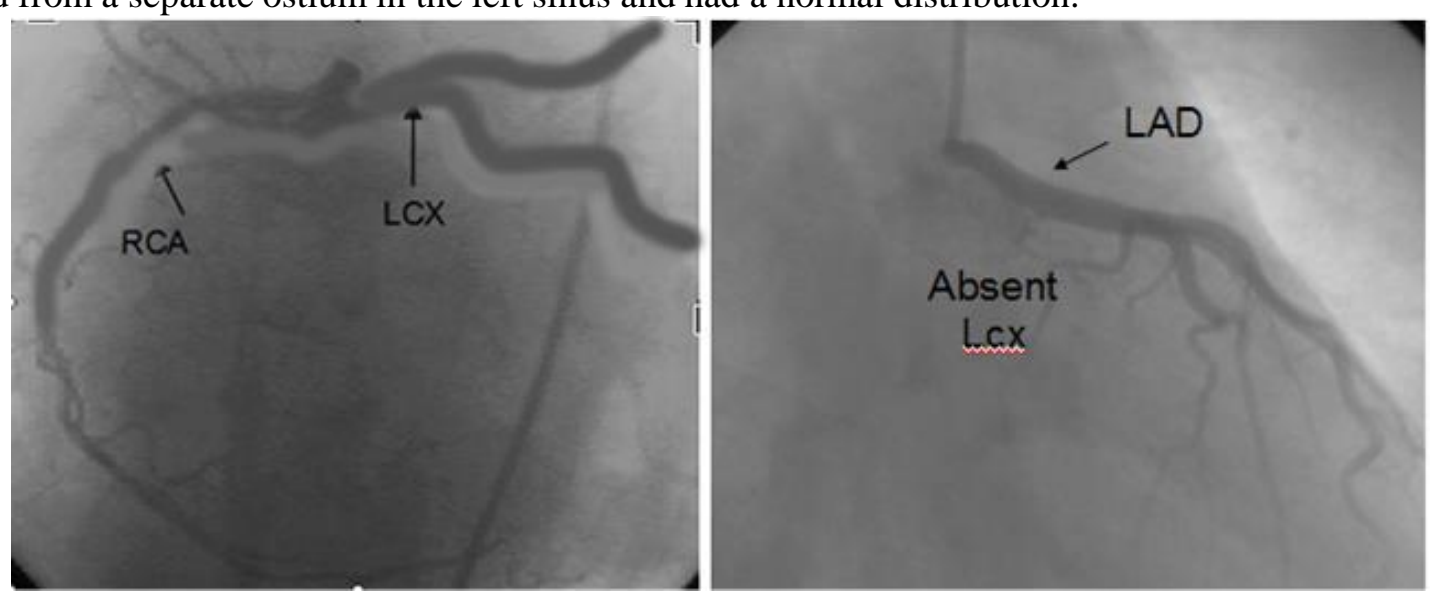

Figure 2: Coronary angiogram showing LM artery gives only LAD, while the LCX arises from right coronary artery. LM: Left main LAD: Left anterior descending RCA: Right coronary artery

LCX: left circumflex 
The second most common anomaly was myocardial bridge and it was present in 31 patients $(\mathbf{0 . 7 3 \%})$ with an angiographic incidence of (26.9\%). Myocardial bridging, defined as intramyocardial tunneling of the epicardial coronary segments as it runs through the myocardium, was identified in 8 females and 23 males, their age ranged between 28 and 47 years (mean $=39.5 \pm 10.5$ years). Ninteen cases were in left anterior descending (LAD) territories as it shown in fig.(3), 15 at Mid-LAD segment, 3 at proximal LAD, and one cases in distal LAD segment. Four cases were observed in right coronary artery, while it was observed in both LAD and RCA in eight cases.

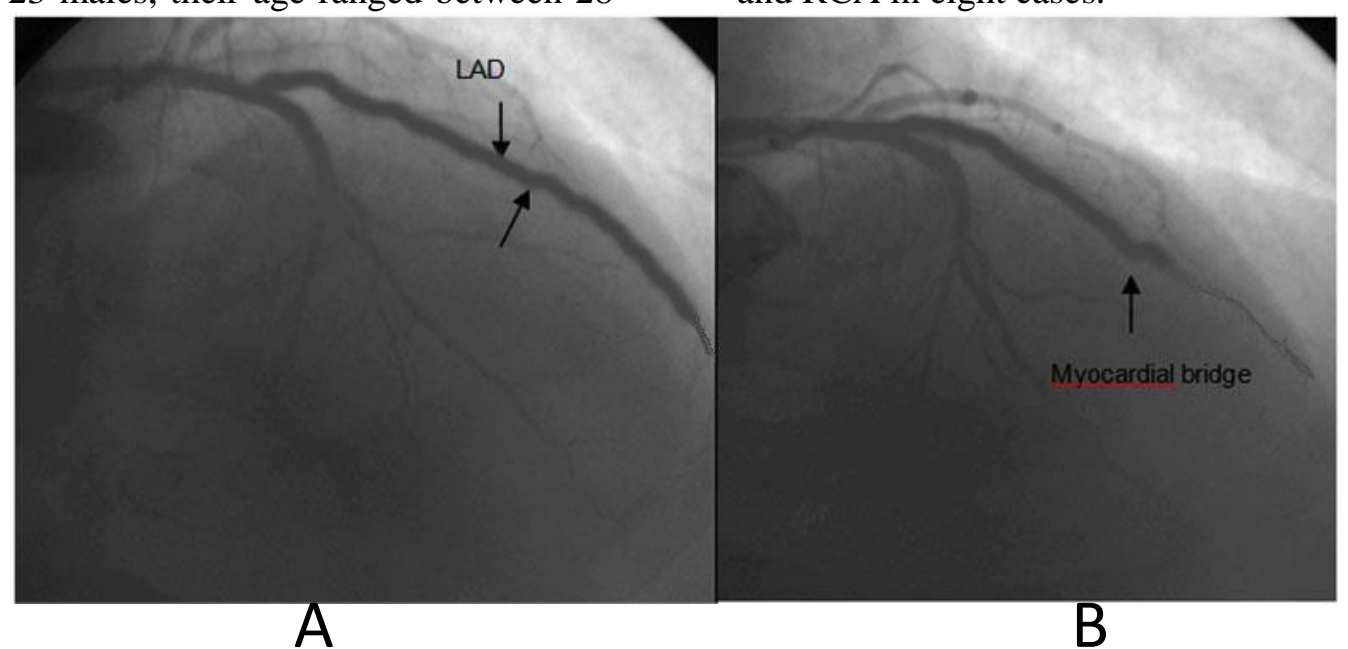

Figure 3: Coronary angiogram showing myocardial bridge in $\mathrm{LAD}$, the figure shows diastolic (A) and systolic (B) frames. The dye became faint during systole due to occlusion of the artery by muscle bridge.

LAD: Left anterior descending

Anomalous RCA was present in eighteen patients $(15.65 \%)$ with an angiographic incidence of $(0.423 \%)$. The origin of RCA arises from left system in 10 patients ; from left coronary sinus (LCS) in 6 cases, and from LAD in 4 cases as shown in fig.(4). Anomalous RCA from posterior coronary sinus (PSV) where present in 8 patients. The artery always coursed between the aorta and the pulmonary artery. Its final distribution was normal in all cases. Moreover, the origin and distribution of the left coronary artery were also normal.

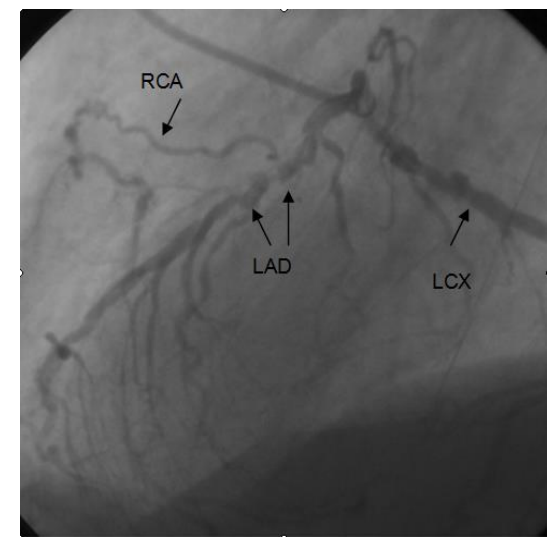

Figure 4: Coronary angiogram showing RCA arises from LAD which shows stenotic lesion just distal to the origin of RCA.

RCA: Right coronary artery

Left main coronary artery was abscent in two cases $(1.7 \%)$ and its two terminal branches ( LAD and LCX) arise separetely from left coronary sinus. and it has anomalous origin from right coronary sinus (RCS) in another two cases $(1.7 \%)$. On the other
LCX: Left circumflex hand, anomalous LAD was present in 8 patients $(6.95 \%)$ with angiographic incidence of $(0.188 \%)$. It was originating from the RCS and coursing anterior to the right ventricular outflow tract with normal peripheral distribution in 5 cases. In these 
cases, the LCX artery was originating from the LCS through a separate ostium with normal peripheral distribution, while it was arising from LCX in three cases.

Coronary aneurysms were observed in 10 cases $(8.7 \%)$ with an angiographic incidence of $(0.235 \%)$. Six of these cases have aneurysm in more than one artery while 4 cases have single artery aneurysm, it either single or multible aneurysms .
On the other hand, coronary fistulas were diagnosed in nine cases $(7.8 \%)$ with an angiographic incidence of $(0.21 \%)$. In these cases, 4 fistulas are connected to right ventricle two cases have multiple coronary fistulas arise from LCX, one from LAD and the other from RCA, 3 are connected to LA (all arise from RCA) and 2 cases have single coronary fistula connected to either RV or RA (one arises from RCA and the other arises from LCX)as shown in fig.(5).

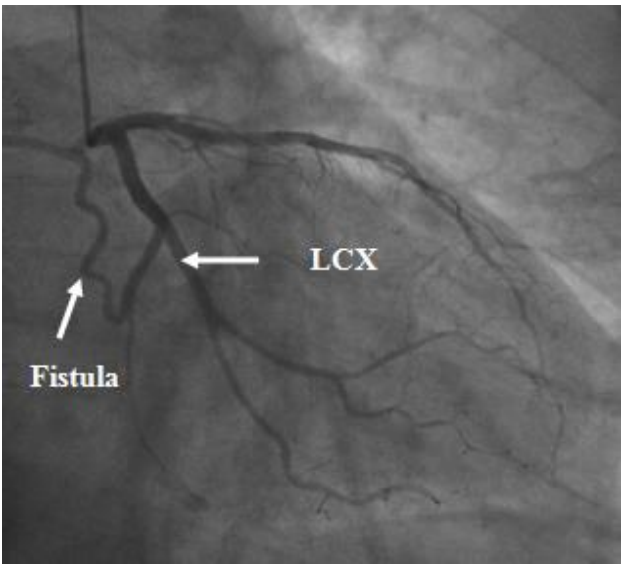

Figure 5 : Coronary angiogram showing fistula arising from LCX and connected to left atrium.

LCX: Left circumflex

Table (2): The distribution of coronary artery anomalies among patients with CAD versus those without CAD.

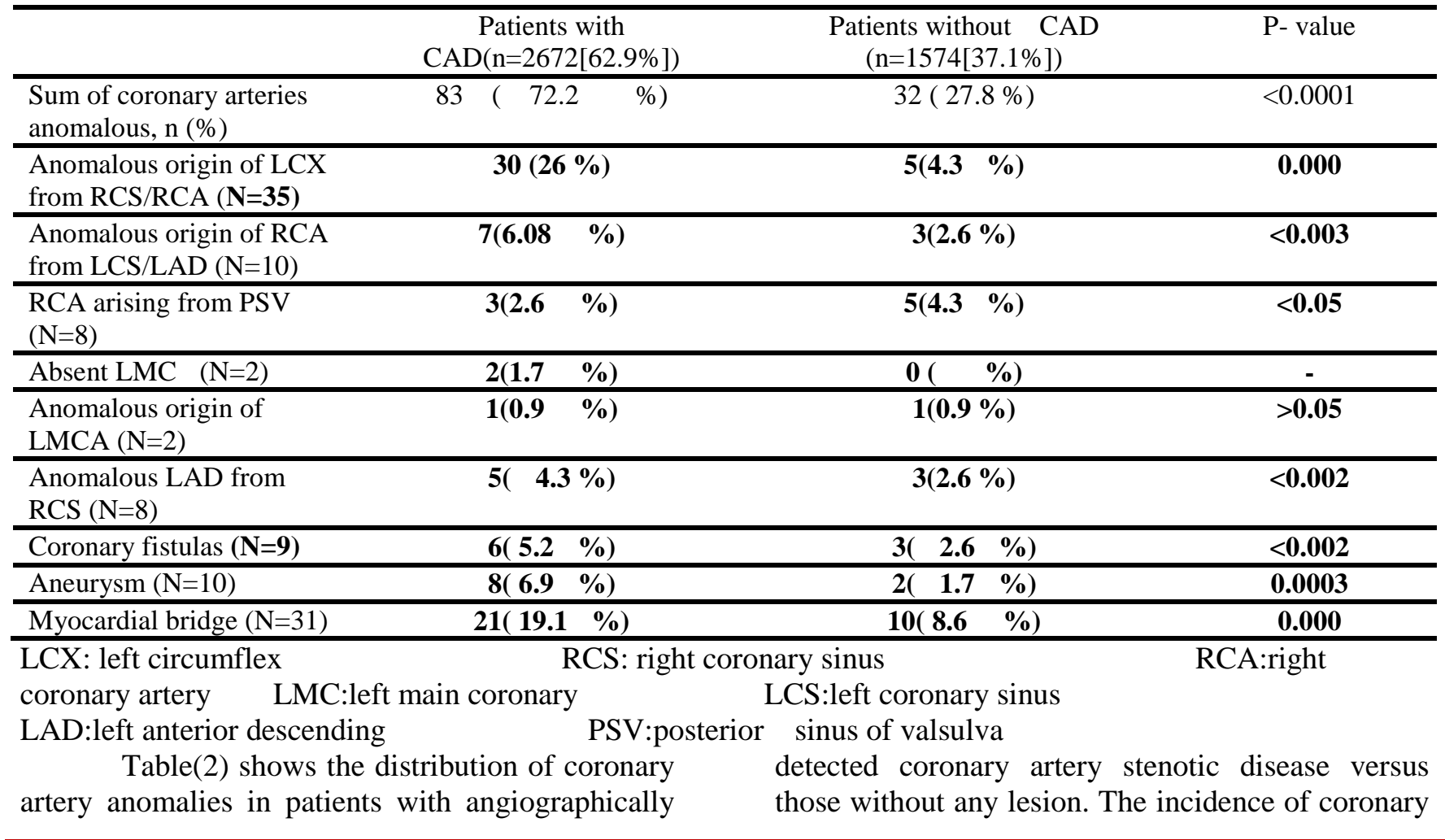


anomalies among cases with coronary artery detected disease was $72.2 \%$ (83 cases) while this incidence among those without angiographically detected coronary artery disease was $27.8 \%$ (32 cases). Hence, the frequency of coronary artery anomaly was significantly higher among patients with CAD than those without CAD ( $\mathrm{P}<0.0001)$.
Thirty cases (26\%) had anomalous LCX ,10 cases (8.69\%) had anomalous RCA, 3 cases $(2.6 \%)$ had LM coronary anomaly, 5 cases $(4.3 \%)$ had anomalus LAD from RCA, 6 cases $(5.2 \%)$ had Coronary fistulas, 8 cases( $6.9 \%$ ) had coronary artery aneurysm and 21 cases( $19.1 \%)$ had myocardial bridge.

Table (3): Comparison of the presence of significant coronary artery disease (CAD) between normal and anomalous vessels

\begin{tabular}{lccc}
\hline & Number & Percentage & P-value \\
\hline $\begin{array}{l}\text { CAD in anomalous vessel } \\
\text { only }\end{array}$ & 59 & $\mathbf{5 1 . 3 \%}$ & $<0.001$ \\
\hline CAD in normal vessel only & 24 & $\mathbf{2 0 . 8 \%}$ & \\
\hline
\end{tabular}

It was checked whether the presence of coronary vessle anomaly has a relationship with the development of CAD. Our results revealed that the anomalous vessle has a highly significant incidence for the development of CAD than the normal one ( $\mathrm{p}$ value $<0.001$ ). Table (3).

\section{DISCUSSION}

In the present study, 115 coronary angiographies out of 4246 patients revealed a primary congenital anomaly, an incidence of $2.7 \%$ that is higher than usually reported in other studies $(0.6-1.3 \%)^{(3,4,5)}$. The study with the largest angiographic population was that of Yamanaka \& Hobbs, 2002, ${ }^{(4)}$ who reported an angiographic incidence of $1.3 \%$. However, since there is no clearcut classification and widely adopted criteria, there are differences in the methodology of these studies. Some of them include the absence of left main coronary artery as an anomaly(Kardos et al., 1997 and Angelini, 2002) ${ }^{(5,6)}$,others exclude it as they regard it to be a common variation and not an anomaly ${ }^{(7)}$. The study with a clearly stated methodology and the strictest criteria for assessing coronary normality/abnormality is that of Angelini et al $\mathbf{2 0 0 2}^{(\mathbf{5}),}$, who reported an incidence of $5.6 \%$ in a population of 1950 patients. Eid et al.,2009 ${ }^{(\mathbf{8})}$ in their arteriographic study in an adult Lebanese population found an overall incidence of $2.04 \%$, before excluding the absence of the left main coronary artery .

Although coronary anomalies may be detected non-invasively by the new methods like multi-slices computed tomography, this is difficult to be used as screening tests. The anomalies are usually detected at coronary angiography ${ }^{(9)}$.

We chose the angiography to detect the coronary anomalies. However, other modalities can serve this purpose. Echocardiography has been proposed as a screening test in young asymptomatic individuals engaged in vigorous activities . After implementing protocols for detection of clinically silent CAAs, Chaitman et al .,1976, Kimbiris et al., $1978^{(7,10)}$ concluded that when specifically sought, a wide range of anomalies can be screened successfully with echocardiography. The main disadvantage is that only the proximal course can be visualised and that a high degree of suspicion is needed. With computed tomography (CT) the course of the entire vessel can be easily visualized.

The most common anomaly in our series was that of LCX coronary artery which comes in accordance with some reports. However, others reported anomalous RCA as the most common one $(3,11)$

These study reported a $(0.423 \%)$ incidence of anomalous RCA in congenital coronary anomalies, which is different from other populations, being highest incidence in Indian and lowest in German populations (0.46 and $0.04 \%$, respectively) ${ }^{(3)}$.

Previous studies reported incidence of anomalous origin of the LCX in adults ranging from $0-1.0 \%$ (12). The angiographic incidence of anomalous LCX was the highest $(1.0 \%)$ in a Central European population while the overall incidence of congenital coronary anomalies was $1.3 \%$ in the same study . In Japan, the angiographic incidence of anomalous LCX was the lowest $(0 \%)$ whereas the overall incidence of coronary anomalies was $0.3 \%$, with the RCA being most commonly affected ${ }^{(3)}$.

These study reported an angiographic incidence of $\mathbf{( 3 0 . 3 4 \% )}$ for anomalous LCX, which account for a 
(0.82 \%) of the overall incidence of congenital coronary anomalies. Thus, our angiographic incidence of anomalous LCX is more similar to the Asian and Turkish population than to the American and Central European populations, likely due to genetic or ethnic factors. The anomalous LCX artery always coursed posterior to the aorta to reach its normal distribution and its course was typical in all our patients. This anomaly alone causes no functional impairment of the myocardium, and it is therefore considered benign ${ }^{(3)}$.

In the present study, the LAD of 8 patients (6.95 \%) was arising from the RCA or the RSV. In this anomaly, interarterial course of the LAD between the aorta and pulmonary artery can be the reason for performing angiography for these patients by causing ischemia without the presence of CAD.

Inspite of anomalous left anterior descending artery is one of the rarest anomalies ${ }^{(13)}$ we found it in eight patients. The functional significance of this anomaly is unknown; however, it was reported to occur more commonly in association with tetralogy of Fallot ${ }^{(3)}$. Accurate identification of origin and course of anomalous coronaries is mandatory before planning coronary interventions, so that an appropriate guiding catheter, wire advancement and balloon systems may be selected ${ }^{(3)}$.

Myocardial bridging was significantly encountered in the present study $(0.73 \%)$. Myocardial bridging is defined as an intramyocardial segment in the course of a major epicardial coronary artery ${ }^{(14)}$. The most common site of bridging is in the middle segment of the LAD artery ${ }^{(15)}$.

Coronary artery Aneurysm:With the widespread use of coronary angiography, the incidence of coronary aneurysm was clearly delineated to be 1$5 \%{ }^{(16)}$. In the largest series from the CASS registry, Swaye et al., $\mathbf{1 9 8 3}^{(\mathbf{1 7 )}}$ found coronary aneurysm in $4.9 \%$ of more than 20000 coronary angiograms. The incidence of coronary aneurysm in an Indian patient cohort with ischemic heart disease has been reported to exceed $10 \%{ }^{(\mathbf{1 8})}$. In these study, the incidence of Coronary artery aneurysm was $(8.7 \%)$. Aneurysms may be with a higher risk of rupture or thrombosis. ${ }^{(\mathbf{9}) \text {. }}$

Coronary artery fistulas (CAF):CAF are rare congenital anomalies ${ }^{(20)}$. The incidence is around $0.002 \%$ in the general population and $0.3 \%$ to $0.4 \%$ in patients with congenital heart defects ${ }^{(21)}$. The
CAF incidence in our study was $(0.212 \%)$ among patients undergoing diagnostic coronary angiography. CAF consist of a communication between a coronary artery and a cardiac chamber or a great vessel. In CAF, blood diverting from the high resistance myocardial capillary bed into the low resistance fistula produce ischemia and coronary steal phenomenon, More than $90 \%$ of fistulas drain into the systemic venous side of the circulation ${ }^{(22)}$.

Interestingly, our results show a significantly higher incidence of coronary stenosis in anomalous versus normal vessels, which is in contrary to previous findings. $(\mathbf{1 9 , 2 3 )}$

\section{REFERENCES}

1. Basso C., Maron B.J., Corrado D., and Thiene G. (2000) : Clinical profile of congenital coronary artery anomalies with origin from the wrong aortic sinus leading to sudden death in young competitive athletes. J Am Coll Cardiol. 35:1493-150.

2. Snedecor G.W. and Cochran W.G. (1980): Statistical methods. 7 th Ed. Allid pacific, Bombay.

3. Garg N., Tewari S., Kapoor A., Gupta D.K. and Sinha N. (2000): Primary congenital anomalies of the coronary arteries: a coronary arteriographic study. International Journal of Cardiology. 74(1):39-46.

4. Yamanaka O. and Hobbs R.E. (1990): Coronary artery anomalies in 126,595 patients undergoing coronary arteriography. Catheterization and Cardiovascular Diagnosis. 21(1):28-40.

5. Angelini P. (2002): Coronary artery anomalies--current clinical issues: definitions, classification, incidence, clinical relevance, and treatment guidelines. Tex Heart Inst J. 29(4):271-8.

6. Chaitman B.R., Lesperance J., Saltiel J. and Bourassa M.G. (1976): Clinical, angiographic, and hemodynamic findings in patients with anomalous origin of the coronary arteries. Circulation. 53(1):122-131.

7. Kardos A., Babai L., Rudas L., Gaal T., Horvath T., Talosi L., Toth K., Sarvary L. and Szasz K. (1997): Epidemiology of congenital coronary artery anomalies: a coronary arteriography study on a central European population. Catheterization and Cardiovascular Diagnosis. 42(3):270-275.

8. Eid A.H., Itani Z., Al-Tannir M., Sayegh S. and Samaha A. (2009): Primary congenital anomalies of the coronary arteries and relation to atherosclerosis: an angiographic study in Lebanon. J Cardiothorac Surg. 4:58: 1-7. 
9. Gehling G., Pohle K., Ropers D., Maeffert R., Regenfus M., Moshage W., Schuster P., Daniel W.G. and Achenbach S. (2002) Anomalies course of the left main coronary or left anterior descending artery originating from the right sinus of Valsalva: Identification of four common variations by electron beam tomography, Images in cardiovascular medicine. 12:105 (6): e 42-3.

10. Kimbiris D., Iskandrian A.S., Segal B.L. and Bemis C.E. (1978): Anomalous aortic origin of coronary arteries. Circulation. 58(4):606615.

11. Zhang F., Ge J.B., Qian J.Y., Fan B., Wang Q.B. and Chen H.Z. ( 2005): Frequency of the anomalous coronary origin in the Chinese population with coronary artery stenosis. Zhonghua Nei Ke Za Zhi.44(5):347-9.

12. Ge J., Jeremias A., Rupp A. , Abels M. , Baumgart D., Liu F., Haude M., Görge G., von Birgelen C., Sack S. and Erbel R. (1999): New signs characteristic of myocardial bridging demonstrated by intracoronary ultrasound and Doppler. European Heart Journal. 20:1707-16.

13. Aydinlar A., Cicek D., Senturk T., Gemici K, Serdar O.A., Kazazoglu A.R., Kumbay E. and Cordan J. (2005): Primary congenital anomalies of the coronary arteries: a coronary arteriographic study in Western Turkey. International Heart Journal. 46(1):97-103.

14. Ko S.M. (2008): An overview of myocardial bridging with a focus on multidetector CT coronary angiographic findings.Korean Circ J. 38:583-9.

15. Ko S.M., Choi J.S/ , Nam C.W. and Hur S.H. (2008): Incidence and clinical significance of myocardial bridging with ECG-gated 16-row MDCT coronary angiography. Int J Cardiovasc Imaging. 24(4):445-52.

16. Cademartiri1 F., Runza G., Luccichenti G., Galia M., Mollet NR., Alaimo V., Brambilla
V., Gualerzi M., Coruzzi P., Midiri M. and Lagalla R. (2006): Coronary artery anomalies: incidence, pathophysiology, clinical relevance and role of diagnostic imaging. Radiol med.111:376-39.

17. Swaye P.S., Fisher L.D., Litwin P., Vignola P.A., Judkins M.P., Kemp H.G., Mudd J.G. and Gosselin A.J. (1983): Aneurysmal coronary artery disease. Circulation. 67:134138.

18. Sharma S.N., Kaul U., Sharma S., Wasir H.S., Manchanda S.C., Bahl V.K., Talwar K.K,. Rajani M. and Bhatia M.L. (1990): Coronary arteriographic profile in young and old Indian patients with ischaemic heart disease: a comparative study. Indian Heart J. 42:365-9.

19. Mustafa Saglam (2008): Identifying cardiovascular risk factors in a patient population with coronary artery ectasia. Angiology. 58:698-703.

20. Frommelt P.C. and Frommelt M.A. (2004): Congenital coronary artery anomalies. Pediatr Clin North Am. 51(5):1273-1288.

21. Cherif A., Farhati A., Fajraoui M., Boussaada R., Hmam M., Ezzar T., Mourali S. and Mechmeche R. (2003): Coronarypulmonary arterial fistula in the adult: report of 6 cases and review of the literature. Tunis Med.81(8):595-599.

22. Levin D., Fellows K.E. and Abrams H.L. (1978): Hemodynamically significant primary anomalies of the coronary arteries. Angiographic aspects. Cir. 58:25-34.

23. Lev Lubarsky, Manish Prakash and Ali Ahmad (2006): High Prevalence of Myocardial Bridging: Evaluation by MDCT Coronary Angiography. Circulation.114: II;692. 


\section{الملخص العربي}

يمكن تعريف التغير ات التشريحية للشر ايين التاجية على أنها "أي اختلاف في المنشأ أو المسار أو كليهما معًا أو في عدد الثر ايين أو غير ذلك من الاختلافات". وتساعد وسائل التشخيص الحديثة على تحديد هذه الاختلافات.

الهدف من هذا العمل هو دراسة طبيعة الثر ايين التاجية والتغيرات التشريحية لها عن طريق التصوير الوعائي للثر ايين التاجية (القسطرة

التشخيصية).

وقد تم إدر اج أي حالة سجلت في وحدة قسطرة مستشفي جامعة الزقازيق في هذه الدر اسة. وتم عمل در اسة وصفية لعدد T؟ ؟ ؟ حالة من مستشفي جامعة

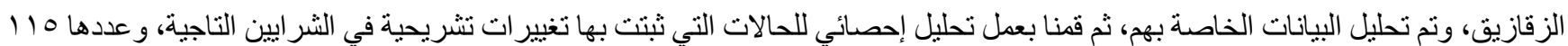

حالة.

حالات الأو عية التاجية الثناذة في سكان محافظة الثرقية أعلى من التي تم رصدها في غير هم من السكان ـ و كان الثذوذ الأكثر شيو عا هو شذوذ الثريان التاجي الدائري وجسر عضلة القلب كما هو الحال في الدر اسات الأخرى. وقد تم رصد حالات كثيرة من أمر اض الثر ايين التاجية في الثر ايين التاجية ذات التغير ات الخلقية. التوصيات:

تحديد نوع الثذوذ في الثر ايين التاجية يرتبط ارتباطاوثثقا بمؤشر الاشتباه السريري. وبالتالي، فمن المستحسن أن المرضى الأحياء ينبغي أن يخضع للمر اقبة على المدى الطويل لتوضيح التاريخ الطبيعي الثذوذ وتأثير أبي تدخل عليه. 